\title{
The SWOT Analysis of Chinese Yong Hui Supermarket Chain
}

\section{Development Strategy Research}

\author{
Ying LI \\ Fujian Polytechnic of Information Technology, China
}

\begin{abstract}
As the China's retail industry opening to the outside world and the foreign large chain supermarket pouring in, making the fierce competition even more severe. Some big supermarket chains has been lost in the plight of survival. Therefore, in order to promote the fast and healthy development, improving the market competitiveness and seeking new development ways has become a big issue. This article uses the Yong Hui supermarket as the research object, which is the model of China "agriculture to super" promotion. We use the SWOT method to analyze the interior and exterior environment and put forward some strategic decisions, which may have some practical significance.
\end{abstract}

KEYWORD: SWOT analysis; Yong Hui supermarket; Chain; Development strategy; Research

The SWOT analysis has been put forward by professor Weihrich in the early $1980 \mathrm{~s}$. It refers to a comprehensive consideration of the internal conditions and external environment factors of an enterprise, system evaluation, in order to select the best way of operating strategy. Here, S refers to the internal advantage (Strengths), $\mathrm{W}$ is refers to internal disadvantage (Weaknesses), $\mathrm{O}$ refers to external opportunity (Opportunities), $\mathrm{T}$ is refers to the threat of external environment (Threats).

\section{YONG HUI SUPERMARKET INTRODUCTION IN CHINA}

Yong Hui supermarket was founded in 2001.Through ten years of leap development, it has become one of the top 500 enterprises in China. winning the" China well-known trademark ", the "national May 1 labor certificate" and other honorary titles. Shanghai main board listing (stock code: 601933). Young Hui is one of the first batch of supermarket in mainland China, which introduces the fresh agricultural products. Besides, Yong Hui has been awarded as the "agriculture to super" promotion model by seven ministries and commissions of the state in China.

Yong Hui has developed into as a large-scale group enterprise, which making the retail as the top leader, taking modern agriculture and food industry as the two wings, and it is supported by modern logistics. Yong Hui supermarket adhere to the "sharing" fusion, creating the common prosperity of China's retail market with domestic or foreign retail enterprises, It currently has developed nearly 500 chain stores, in FuJian, ZheJiang, and other 17 provinces and cities and has operating area of more than 4 million square meters, ranking 13 of top chain enterprises of China in 2013.

\section{THE SWOT ANALYSIS OF CHINESE YONG HUI SUPERMARKET CHAINS}

\subsection{Advantage Analysis}

1)YongHui Supermarket adopt development strategies "first and then the development of regional stability expansion" and the implementation of "guaranteed fresh food" business strategy;

2)The position clear to operate as the most prominent feature of fresh goods, implementation supermarkets, stores and community supermarkets as the core format, convenience stores franchise supplemented, and build open up food processing and modern agriculture combines chain;

3)Establish a set of comprehensive national and regional fresh produce direct mining system, internal commodity preservation research institutions, which greatly limits to reduce intermediate links "in origin - the customer - the store," the fresh produce industry chain, reduce the logistics, warehousing and loss costs, maintain a maximum degree of color, flavor and to help 
consumers competitively priced, but also gradually change the store area surrounding residents to purchase fresh items habits.

\subsection{Inferior Analysis}

1)Employee's service levels and awareness needs to be improved, the level and efficiency of management needs to be improved;

2)Low market positioning, positioning the general public, limited spending power of the population;

3)In a large-scale cross-expansion, the distribution has been lacking;

4)Rental growth, especially growth in Fujian's old stores and growth pressures and labor costs;

5)The high-end talent scarcity.

\subsection{Opportunity Analysis}

1)The Chinese government actively promoted;

2)HSBC as the largest shareholder of YongHui supermarket, it provided a strong financial support for YongHui development; social and technological progress, to provide technical support;

3)Due to the improvement of people's living standards, so as to promote sales;

4)Learn successful management experience from abroad.

\subsection{Threat Analysis}

1)Competition. With the full opening of China's retail industry, some of the world's leading formats are constantly being introduced, compared with foreign, Domestic retail enterprises in terms of financial strength, scale of operation, management experience, or in terms of logistics, information technology, there is a relatively large gap, chain enterprises are facing competitive pressures of the international market;

2)Chinese fresh produce supermarket operators still in the exploratory stage.

\section{THE DEVELOPMENT STRATEGY OF YONG HUI}

\subsection{The combination of mutual benefit and "win- win" strategy}

With combination, mutually beneficial and "winwin" as the goal, Yong Hui aims at strengthening the big market network retail industry .It needs to develop the procurement bidding system and a joint procurement team, and conduct the logistics base and ChongQing area business cooperation. To set up the exchange of learning mechanism and develop the mutually beneficial and win-win mode of strategic cooperation, gives the full plays of both sides in the leading area, such as market network, information logistics and so on ,in order to realize common development and win-win cooperation.

Yong Hui supermarket teamed up with ZhongBai group. ZhongBai group is supermarket chain in domestic business of listed companies, which is one of 20 large-scale circulation enterprises supported by the ministry of commerce throughout the country. And it is one of the largest retail chains in Hubei province. ZhongBai group has chain companies more than 1000 business outlets, business area of more than 200 square meters, nearly 100000 kinds of varieties, and has 120000 square meters, normal temperature logistics warehouse and warehouse area of 80000 square meters of fresh logistics park.

Another example is that Yong Hui supermarket cooperated with the milk international. Milk international was founded in 1886, from the earliest dairy products to focusing on the retailing in recent years, now has become a considerable size of the retail enterprises in Asia, business in Hong Kong, Taiwan, Singapore and other place

Through much cooperation, Yong Hui supermarket introduces a number of high-end seafood imports high-quality goods category, such as, beef, fine fruits in shelf and constantly enriches the storage and recommends the "we-chart shop". Building strong commodity supply chain, in such aspects as fresh, food supplies for global sourcing, not only brings Yong Hui motivation of sustainable development, and also greatly satisfies the consumers of imported classes, and other characteristics of food demand, to improve the product quality of the Yong Hui supermarket.

\subsection{To strengthen the construction of enterprise culture, highlight the local characteristics}

Enterprise culture is the enterprise core competitive ability. Yong Hui supermarket is developed in the local supermarket, in the competition at the same time to strengthen the construction of enterprise culture and highlight the local characteristics. Yong Hui from development course, the enterprise culture, logistics, supply chain system construction and style, etc., passes "to eliminate table pollution, construction trust market" the enterprise idea, and displays "fresh Yong Hui" "trust of Yong Hui", "science and technology Yong Hui", "green Yong Hui". This good image is set up and developed mainly through the study of the corporate culture of staff training, guided by the concept of corporate culture and values to establish management system, making oneself become China's agriculture industry, circulation integration of leading enterprise, and China's most respected companies in the retail industry and best employer.

Yong Hui supermarket has a unique "business model". On the shopping environment, it takes the 
lead in the "fresh" area of the business area of expanding nearly 3000 kinds of agricultural products as the main products. On shopping habits and commodity prices, it keeps the farmer's market price competitive advantage, and meets consumers free shopping habits; In fresh agricultural products business, it keeps the low price and loss, high degree of quality and fresh Yong Hui's success owes to create the Yong Hui model, which combined the traditional farmers' market and the characteristics of modern supermarkets. Both the farmers' market price advantage, and fresh, category complete fresh products, and brings the modern supermarket and comfortable shopping environment and the operation mode of "one-stop" work style shopping experience .This model highlights the local characteristics, and is also the core competitiveness of Yong Hui supermarket.

\subsection{To create new O2O platform innovation consumption}

Yong Hui has always focused on, groping, practice the use of new technologies in the field of retail. As China entered the era of $4 \mathrm{G}$, Yong Hui has seized the new changes and new opportunities brought by the mobile Internet, and officially launched the "Yong Hui we-chat shop". "Yong Hui we-chat shop" is a brand new $\mathrm{O} 2 \mathrm{O}$ business platform, online "store" to purchase, offline "store" to pick up the goods .The first eight staging stores in China Fuzhou area ,in order to bring more simple, rapid and convenient "handheld shopping" new experiences for consumers "Yong Hui we-chat shop" is a new product, and it needs improvement and perfection in practice.constantly updated to upgrade, extensive listening to the advice of customers, to further improve and strengthen the service function. Treat various conditions are mature, and gradually extended to the stores. In the future, Yong Hui will continue to integrate complementary advantages of online and offline resources, and to form a "big data", effective integration of "great logistics", to promote the integration of commodity circulation.

At present, micro Yong Hui store platform members have five core features: (1) electronic, the shopping in the we-chat shop can also be credited to Yong Hui card, and shares the credits (2) the DM and key selected commodity exhibition. With the help of we-chat stores, timely deliver the the latest promotions, and service information; (3) mobile transactions, consumers can log in anytime and anywhere on-line store, using pay treasure, China unionpay and settlement; (4) the electronic coupons. The consumers get electronic coupons, combined with the offline entity stores used interchangeably, so the members can enjoy more favorable advantages (5)Rapid payment in mobile the customers who shop in the real store , can use mobile phones to pay online .

Consumers can online experience. Consumers with 3G, 4G mobile search download "Yong Hui we-chat shop" online experience, only three steps can quickly complete a shopping: first step is to choose and buy online:"Yong Hui we-chat shop" the first line of 500 a variety of goods, including delicate packaging of fresh vegetables, fruits, meat and poultry, ice, drinks, beverage, detergent, household items, etc., and red sturgeon, cherries, candied fruit, rare mushroom products, such as giving gift box, a large number of high quality and low price goods, will make the consumers gain more surprises. The second step is to make payment: support paypal, China union pay online payment. The third step is to store delivery: consumers online place an order for 2 hours to selected store delivery, stores have opened Yonghui we-chat shop delivery area, specialized service personnel to help consumers prepare goods. At the beginning of this gens going to work is very busy, crowded and shopping in the supermarket, whenever and wherever possible "YongHui we-chat shop" to buy is very convenient. For the convenience of the consumer experience, Wing Fai has been in Fuzhou dawn, Fu Xin, Daru family, Waring, five four North, WORLDTEX, Jin Xiang, Jiangnan Water 8 stores opened "WIFI" network, set up headquarters in the "service hotline Yonghui wechat shop".

Yong Hui store opens a distribution, which is important part of quality service:the seamless connection of online and offline shopping. There are 5 stores in $\mathrm{Fu}$ Zhou set up distribution zone counters, with five times a day. There are hundreds of professional delivery personnel, to ensure that consumers get the high quality and convenient delivery service. Distribution activities, improve operation to the strategic level from procurement, warehousing, logistics, operations, and such links to make careful deployment, and to take this opportunity to enhance operational level and service quality, achieving 020 compaction quality supply chain operation mode. Yong Hui supermarket with the understanding of the commodity and the professional data analysis and combining the modern Internet technology provides consumers with high-quality products, and service. This is Yong Hui fundamental orientation of products and services of we-chat shop.

\subsection{To move online retail of supermarket with fresh food}

Fresh food is the core of Yong Hui supermarket goods. There is a huge market in fresh areas, the management of fresh food becomes the core of supermarket stores strategic transformation development. Today, Yong Hui substantive 
supermarkets in the core fresh goods management will continue to intensify efforts to consolidate the foundation, strengthen and optimize the selfmanagement system, solid foundation work to attract customers. At current, cold chain system and distribution system still cannot meet the fresh goods storage and transportation in limited effective coverage .To satisfy the consumers attaching great importance to the environment and safety and fresh of product in short effective time, Yong Hui found the "vacuum zone" of their own competitive advantage. Fresh food requires higher logistics efficiency in a short period of time, fresh products transportation, after the supermarket gradually realizing the chaining operation, projects in the establishment of the logistics distribution center and mining to the display data of commodity. Building own food processing park and vegetable base can save procurement costs and improve delivery quality and on time; with the rise of fresh electric business, the market increases fierce competition, so Yong Hui with fresh food moving online retail can bring continuous consumption, attention to electricity and stable sentiment to maintain the leading industry position.

\section{REFERENCES}

[1] Yonghui supermarket website: http://www.yonghui.com.cn

[2] Lijin,Chen. SWOT analysis of warehouse style supermarket based on membership marketing strategy research -- Taking Fuzhou area as an example. Journal of Huaihai Institute of Techology (SOCIAL SCIENCE EDITION). 2014 (06)

[3] Jianguo,Gu. Leveraging the online retail supermarket with fresh product. Retail Technology

[4] LinLi, Hui Fujian Yong Hui supermarket marketing strategy research. Xiamen university, business management. $2014(04)$ 